\title{
Mito E TRAdiçÃo LITERÁRIA NA POESIA DE CLÁUDIO MANUEL DA COSTA
}

\author{
Andréa Sirihal Werkema* \\ Universidade Federal de Minas Gerais
}

\begin{abstract}
RESU M O
Este trabalho procura traçar alguns aspectos das relações entre a tradição mítica greco-romana e a tradição literária europeia na poesia de Cláudio Manuel da Costa, verificando as funções particulares exercidas pelo mito e pela literatura na convenção neoclássica universalizante que reveste a poesia do autor mineiro.
\end{abstract}

\section{PALA VRAS - CHAVE}

Mito, Tradição, Neoclassicismo

uso recorrente dos mitos de procedência greco-romana nas literaturas ditas clássicas é facilmente verificável. O que nem sempre se verifica são as formas e estratégias usadas por períodos e autores literários que se apoderaram dos temas mitológicos e os colocaram em uso. Em autores capazes de maior elaboração, a utilização do mito transcenderá o mero ornamento, tendendo a adquirir uma consistência orgânica no texto literário, isto é, tornando-se parte integrante de um texto que, mesmo muito posterior e isento de conotações não literárias, tem em tal mito uma analogia emocional ou situacional, criando assim um paralelismo enriquecedor que situa o texto e mantém vivo o mito, através de sua transformação em novos materiais: "Uma fixação durável, só a escrita a oferece, a qual, no entanto, empreende simultaneamente a tarefa de suplantar a comunicação mítica por meio de novas formas do saber."1

A tradição mitológica de origem grega passou por diversas filtragens através dos tempos. Foi transformada em matéria dramática e literária pelos poetas e discutida pelos filósofos, e, através deles, criou-se um corpus extenso que chegou até nós e serviu como base para boa parte do imaginário ocidental. Há um longo caminho percorrido ao longo da tradição grega clássica, entre a funcionalidade do relato mítico primitivo e a narrativa mítica literariamente arranjada. Já nos textos homéricos e, posteriormente, nas grandes tragédias gregas, o mito é reaproveitado enquanto material estético, e passa a exercer funções políticas e literárias. Se Homero foi censurado pelos filósofos, seus admiradores, pela liberdade com que traçava os perfis dos deuses olímpicos, o foi por questões morais; e os primórdios da tragédia, que estariam ligados ao culto de Dionísio, já começavam a se perder para autores tão eruditos quanto Ésquilo, Sófocles e Eurípides. A criação ficcional se

\footnotetext{
*aswerkema@hotmail.com

${ }^{1}$ BURKERT. Mito e mitologia, p. 20.
} 
encontra presente, e de modo bastante claro, em textos que se referem a mitos amplamente conhecidos: "(...) Sófocles teve de transformar os dados lendários, afastando este ou aquele episódio, esta ou aquela versão incompatível com esta experiência única que ele instituía. Nas suas mãos, o mito tomou forma e, da argila imprecisa que lhe fornecia a tradição, Sófocles modelou um Édipo imortal.” É na diferença mesma, no delineamento ético-psicológico de personagens mortais e imortais, que se encontra a marca de um autor.

O trabalho literário sobre as fontes míticas teve o papel não só de fixar, como de modificar e transmitir as lendas. Isso porque as criações e modificações introduzidas por vários autores, lidos a posteriori e portanto integrantes de uma tradição, acarretaram, inevitavelmente, acréscimos morais e éticos, ou associação de virtudes ou defeitos a determinados personagens míticos, que assim foram mais facilmente apreendidos pelos seus pósteros (Ulisses está para sempre associado à astúcia; o deus Apolo preside as artes e medicina, mas também espalha as pestes e inflige a vingança justa, por exemplo). A primeira grande transformação sofrida por esse corpus helênico se dá na cultura romana, que adaptou as narrativas familiares e os nomes dos deuses gregos de modo a torná-los antecedentes de seu próprio povo. Com isto, reviveram, via tradição literária, uma das funções essenciais do mito: a de narrativa fundacional. Os grandes poetas latinos não hesitaram em buscar nas epopeias e tragédias gregas as cidades e os homens de que teriam derivado Roma e os romanos. Assim, ao fugir de Troia em chamas, Enéias teria iniciado um longo trajeto que desembocaria na grandeza romana, segundo o poema fundamental de Virgílio. Usando o tema da metamorfose (para sempre associada aos elementos da natureza), Ovídio daria à luz uma epopeia de mitos entrelaçados que explicariam a criação do mundo e do homem, cujo ápice se daria sob o mando de Augusto. Desses dois poetas principalmente, e também das prescrições temático-formais de Horácio, derivou quase toda a tradição literária europeia que convencionamos chamar de "clássica", desde os vários Renascimentos até os últimos suspiros parnasianos, passando pelo Barroco e pelo Neoclassicismo (em contraposição às literaturas modernas de índole "romântica").

Os mitos, portanto, nas acepções mais difundidas da palavra ("mito é narrativa aplicada”), não mantêm a sua funcionalidade nas literaturas clássicas europeias. Os textos literários revestem-se de uma capa mitológica ornamental na maioria das vezes, ou recorrem aos temas gregos para exemplificar, no sentido moral do termo, comportamentos louváveis ou condenáveis - contrariando, dessa forma, a habitual impermeabilidade significatória do mito, que não se deixa decifrar facilmente. Mas em alguns autores (como já em Virgílio e Ovídio), encontraremos a vontade de reviver, por analogia, o mito em suas funções primeiras, seja a de “'carta de fundação' de instituições”, a de "explicação de rituais”, ou a de "esboço de reivindicações familiares ou étnicas". ${ }^{4}$ Assim, através da fabulação literária, o homem ocidental moderno preencherá muitas das lacunas deixadas pelo seu afastamento irreversível das narrativas fundadoras da Antiguidade.

Interessa-nos neste momento as configurações que a tradição latina de procedência grega tomou em fins do século XVII, atravessando a quase totalidade do século dito das

\footnotetext{
${ }^{2}$ GRIMAL. A mitologia grega, p. 133

${ }^{3}$ BURKERT. Mito e mitologia, p. 18.

${ }^{4}$ BURKERT. Mito e mitologia, p. 18.
} 
Luzes. Diversas formas de pensamento foram atingidas por um novo e fortíssimo "retorno" à Antiguidade clássica tal como entendida pelos modernos setecentistas. Claro está que o ideal clássico não deixou nunca de estar presente nas literaturas europeias, mas tomou diferentes configurações através dos tempos: no século XVIII, liga-se claramente a uma alternativa à tutela da Igreja, e reveste-se de propósitos não apenas eruditos, como também políticos. ${ }^{5}$ Se o pensamento político-filosófico da época foi marcado por traços progressistas e libertários, em luta por um mundo melhor para os homens (espelhado, até certo ponto, no mundo mítico da Antiguidade), luta que evoluiu até os acontecimentos de 1789 na França, as artes plásticas procuraram o lado mais ornamental e descompromissado da idade de ouro perdida nas Grécia e Roma clássicas.

Já a literatura tentou o equilíbrio entre o prazer e o aprendizado, seguindo os princípios de Horácio, e ilustrou muitos de seus textos com cenas da vida pastoril em uma Arcádia idealizada. É nessa mistura de seriedade pedagógica e trejeitos árcades que se situa a maior parte da literatura produzida na época. Das óperas de Metastásio aos poemas de Tomás Antônio Gonzaga, é freqüente as divindades e os personagens histórico-míticos apresentarem-se lado a lado com as criações originais dos poetas ou personagens emprestados de seus autores prediletos. Não faz ainda parte das reivindicações neoclássicas a originalidade: a tradição existe, definitivamente, como um manancial de temas, formas, personagens, situações comuns - e um uso compartilhado deste material não é, no século XVIII, motivo de preocupações como será para o século seguinte. A preocupação do autor setecentista está em marcar seus textos pela filiação à literatura clássica - base da tradição ocidental. Para isso, nada melhor que retomar os mitos gregos, transformados em matéria literária por Roma, revisitados pelos renascentistas europeus, e assim por diante. Mas, repetimos, em alguns autores do século XVIII vamos encontrar novamente o uso orgânico dos mitos, agora em sua forma de fábulas literárias, ilustrando, criando paralelos, dizendo pela analogia coisas que não talvez não pudessem ser ditas de forma direta.

No Neoclassicismo literário brasileiro o uso da mitologia greco-romana tornou-se objeto de longas discussões iniciadas pelos primeiros historiadores de nossa literatura, discussões que de certa forma se mantêm até os dias de hoje. De fato, homens como Ferdinand Denis, Varnhagen, Joaquim Norberto e muitos outros, contemporâneos ou devedores da tradição romântica de literatura, não podiam ver com bons olhos o uso de temas notadamente estrangeiros por nossos poetas, quando o material local prometia tantas possibilidades. Não se trata de discutir aqui, novamente, o equívoco cometido por nossos primeiros historiadores da literatura, equívoco facilmente desfeito por qualquer relativismo histórico. ${ }^{6}$ Mas torna-se interessante analisar aquilo que passou despercebido

\footnotetext{
${ }^{5}$ Cf. ARENDT. A vida do espírito, p. 344.

${ }^{6}$ A virada de paradigmas operada no Romantismo foi muitas vezes reduzida a questões menores, como esta da escolha de um temário próprio para uma poesia nacional. Na verdade, os autores românticos mais imbuídos de espírito crítico verão com clareza a presença, e a necessidade, de uma tradição comum herdada por todo o Ocidente. É a partir dela, e no momento certo, que o Romantismo trabalhará os critérios diferenciadores de uma literatura nacional. Mas assim como os românticos tiveram dificuldades em compreender seus antecessores neoclássicos, nos dias de hoje condenamos o Romantismo por seu exagero sentimental e retórico e por seu exacerbado subjetivismo.
} 
para esses autores, em especial as noções de imitação dos mestres e de filiação a uma tradição, tão caras aos poetas do século XVIII, entre eles os poetas das colônias.

A necessidade de elevar a um nível ocidental as produções literárias da periferia colonial, ou a tensão entre os aspectos particulares e universais que marca nossa cultura, no dizer de Antonio Candido, desde seus primórdios, tornaram ainda mais importante para os poetas árcades brasileiros a presença, em seus textos, de marcas da tradição mítico-literária clássica, isto é, universal. ${ }^{7}$

Em um poeta como Cláudio Manuel da Costa, precursor da poesia neoclássica no Brasil, a hesitação entre temas locais e externos casa-se com o próprio drama individual de um erudito nascido nas colônias e educado de acordo com os preceitos europeus, tendo se iniciado na poesia em terras portuguesas. A isso se poderia, talvez, acrescentar uma subjetividade tendente ao dilaceramento emocional, com preferência marcada pelo lado sombrio e infeliz da existência. É o típico intelectual do entrelugar: poeta de transição entre o Barroco e o Neoclassicismo, homem dividido entre a colônia e a metrópole, súdito em dúvida quanto às suas inclinações separatistas. É acima de tudo um erudito de formação clássica, com vastos conhecimentos da bibliografia obrigatória para um poeta de traços neoclássicos.

Na poesia de Cláudio Manuel configura-se a dialética do uso literário do mito como nos melhores autores clássicos: o mito é ornamento, mas é também marca de uma filiação, ou melhor, o mito faz falar antigos personagens, míticos ou de outros autores, mas deixa falar também aquele autor em particular, através de um paralelo entre os respectivos estados emocionais, personalidades e situações. Um bom exemplo é o uso do tema de Polifemo por Cláudio Manuel.

Nome da Écloga VIII, ${ }^{8}$ Polifemo também aparece, de forma indireta, nas Cantatas III e IV ${ }^{9}$ das Obras (1768) do poeta. O monstruoso ciclope, apaixonado pela ninfa Galateia, sofre por ser preterido em seu amor pelo belo pastor Ácis. A figura patética do ciclope evoca toda a linhagem de pastores infelizes da poesia de Cláudio Manuel, que penam até a morte ou se metamorfoseiam em pedra devido ao sofrimento amoroso. $\mathrm{O}$ aspecto disforme de Polifemo, causa de sua não aceitação no universo amoroso, identifica-o à figura do poeta que "enfermou de desgraçado"; além do mais, o tema clássico de Polifemo remete à tradição mítica e poética grega, às Metamorfoses de Ovídio, a Góngora e a Metastásio. ${ }^{10}$ No paralelo entre a persona poética de Cláudio Manuel da Costa e a não adequação de Polifemo às intrigas amorosas configura-se um uso vivo do mito literário, tornado atual pela analogia emocional: "A sua força deriva em parte da circunstância de haver a inspiração encontrado na tradição clássica um mito cujas formas desposou. Quando um mito ou alegoria tradicionais correspondem à emoção poética, esta flui no seu significado, de alcance universal, e a poesia brota mais forte, encontrando correlativo."11

\footnotetext{
${ }^{7}$ Cf. CANDIDO. Formação da literatura brasileira, p. 66-69.

${ }^{8}$ PROENÇA FILHO. A poesia dos inconfidentes, p. 177-178.

${ }^{9}$ PROENÇA FILHO. A poesia dos inconfidentes, p. 296-297.

${ }^{10}$ Conferir a leitura do tema de Polifemo na obra de Cláudio Manuel feita em: CANDIDO. Formação da literatura brasileira, p. 92-96.
}

${ }^{11}$ CANDIDO. Formação da literatura brasileira, p. 96. 
Melhor exemplo da funcionalidade literária do mito encontra-se na "Fábula do Ribeirão do Carmo", ${ }^{12}$ longo poema também publicado nas Obras, em que o tema da metamorfose é usado para explicar o surgimento do "pátrio Rio", o ribeirão aurífero que banha a cidade de Mariana. Aqui, a metamorfose de um mancebo em Ribeirão do Carmo é presidida por Apolo, o deus vingativo, a quem fora consagrada a bela ninfa Eulina, filha de Aucolo. O jovem, filho do gigante Itamonte (transformado em montanha por um Jove também furioso, devido à guerra que travara contra o pai dos deuses), apaixona-se perdidamente por Eulina, e concebe um plano para raptá-la. Rouba do pai uma grande cópia de tesouros e apodera-se da ninfa distraída em seu banho. Imediatamente Apolo intervém, arrebatando Eulina de seus braços. $O$ jovem mancebo, desesperado, rasga o peito com um punhal, mas é transformado por Apolo em rio, que tem a cor turva de seu sangue. $O$ terceiro castigo infligido pelo deus é espalhar a notícia do tesouro contido no seio do Ribeirão, o que ocasiona o seu assalto por homens ávidos de riquezas, que o ferem continuamente.

Duas metamorfoses, a do gigante Itamonte em montanha e a de seu filho em ribeirão, evocam episódios ovidianos: a guerra travada pelos gigantes contra Júpiter (ou Jove), que os arremessou do Olimpo, e as inúmeras transformações dos homens em rios, inclusive a de Ácis, amante de Galatéia, morto por Polifemo. O tema da jovem prometida a Apolo e reivindicada por um mortal aparece na Ilíada, em que Criseide, filha de um sacerdote de Apolo, é roubada por Aquiles, ocasionando a ira do deus contra os gregos. Já os nomes de Aucolo e Eulina não são mitológicos, e sim árcades, presentes na tradição pastoril de poesia. Itamonte (o pico do Itacolomi) e Ribeirão do Carmo são claramente locais, e figuras preferidas por Cláudio Manuel na paisagem mineira, a penha e o rio. Nessa mistura de fontes e referências encontra-se de novo configurada a tensão entre o universal e o particular, que irrompe na obra de Cláudio Manuel como forma de expressar uma ligação afetiva de fundas raízes. ${ }^{13}$ São três planos diferentes da evolução que o mito percorreu na literatura, culminando na criação de um mito indígena, autóctone. Mito literário, nascido em conformidade com toda uma tradição internalizada pelo autor do Neoclassicismo.

O que torna bela e pungente esta fábula (título acertadamente dado ao poema por seu autor) é o encontro desta tradição clássica com as preocupações localistas do poeta mineiro. Nas regiões selvagens em que fora exilado Itamonte, interfere a mão de Apolo, deus ordenador, que pela vingança refaz a hierarquia ameaçada pelo mancebo apaixonado. Desta vingança surge o ribeirão tão caro ao poeta, não por sua beleza e plasticidade, mas, ao contrário, por sua inadequação aos ideais árcades, pela ausência de traços gentis: metonímia da pátria do poeta. Leia-se, desse modo, a passagem do "Prólogo ao Leitor", das Obras, de Cláudio Manuel, de 1768:

\footnotetext{
${ }^{12}$ Fábula do Ribeirão do Carmo. In: PROENÇA FILHO. A poesia dos inconfidentes, p. 120-127.

13 "La conciencia de no tener historia, de trabajar con una tradición olvidada y ajena; la conciencia de estar en un lugar desplazado e inactual. Podríamos llamar a esa situación la mirada estrábica: Hay que tener un ojo puesto en la inteligencia europea y el otro puesto en las entrañas de la patria." PIGLIA. Memoria y tradición, p. 61.
} 
A desconsolação de não poder substabelecer aqui as delícias do Tejo, do Lima e do Mondego me fez entorpecer o engenho dentro do meu berço, mas nada bastou para deixar de confessar a seu respeito a maior paixão. Esta me persuadiu a invocar muitas vezes e a escrever a Fábula do Ribeirão do Carmo, rio o mais rico desta Capitania, que corre e dava o nome à Cidade Mariana, minha pátria, quando era Vila. ${ }^{14}$

Da mesma forma, lamenta-se o Ribeirão do Carmo, ao fim do poema, o não poder equiparar-se ao Tejo ou ao Mondego, por suas águas turvas, e pela ausência das "Ninfas generosas": o que o marca é a ambição humana, a sede do ouro - aqui deixa Cláudio Manuel irromper com força, em meio ao mito e à convenção árcade, a história recente e o presente convulsos da pátria mineira:

Não se escuta a harmonia
Da temperada avena
Nas margens minhas, que a fatal porfia
Da humana sede ordena
Se atenda apenas o ruído horrendo
Do tosco ferro, que me vai rompendo. ${ }^{15}$

O reaparecimento deste tema no poema épico Vila Rica (1773), poema de fundação, evidencia a função do mito literário na obra de Cláudio Manuel da Costa, pela configuração de um ideário mítico próprio, entrelaçado em sua obra poética. No Canto VII do longo poema, a ninfa Eulina reconta o triste episódio às margens do Ribeirão do Carmo $^{16}$ - nesse momento, o ribeirão, criado por Apolo e habitado por ninfa gentil, encontra-se já mais próximo ao ideal civilizatório neoclássico.

Em suas margens há de erguer-se uma cidade e um povo. ${ }^{17}$ A riqueza do ribeirão, que Apolo em sua vingança fizera conhecida de todos, causando o sofrimento do rio ferido por tanta ambição, será, por outro lado, o motivo da presença maciça do elemento europeu em terras mineiras. Em seu modo melancólico e solene, Cláudio Manuel da Costa ilustra com o tema clássico da metamorfose o início da civilização nas brenhas pátrias: mas civilização triste, marcada pela ambição e pela vingança.

A leitura atenta deste episódio na poesia de Cláudio Manuel torna patente o uso político e institucional de um mito, mesmo que já em sua forma propriamente literária. Perpassa por toda a fábula a noção de fundação, de uma pátria, de um povo, de uma cidade. A sobreposição da instituição às terras até então selvagens marca, literariamente falando, uma sujeição das mesmas às "categorias estéticas" universais, a estilização deste mundo "segundo as normas e os arquétipos clássicos", no dizer de Sérgio Buarque de Holanda. ${ }^{18}$ Mas a conformação das Minas Gerais ao ideal estético árcade e neoclássico

\footnotetext{
${ }^{14}$ PROENÇA FILHO. A poesia dos inconfidentes, p. 47.

${ }^{15}$ PROENÇA FILHO. A poesia dos inconfidentes, p. 126. Conferir também o belíssimo soneto II, das Obras, que celebra justamente o "pátrio Rio", p. 51.

${ }^{16}$ PROENÇA FILHO. A poesia dos inconfidentes, p. 415 e p. 416.

${ }^{17}$ Segundo o sonho de Albuquerque no Canto II do poema Vila Rica. In: PROENÇA FILHO. A poesia dos inconfidentes, p. 382-389.
}

${ }^{18}$ HOLANDA. Capítulos de literatura colonial, p. 157. 
é desde sempre tarefa fracassada, já que, por demais revolvida e angulosa, sua paisagem não se deixa assim tão facilmente civilizar - a não ser que pelo esforço hercúleo de aplicação da convenção poética. Mas teríamos em Cláudio Manuel da Costa uma sensibilidade poética fina demais para suportar o achatamento redutor da convenção; a sua poesia, portanto, deixa transparecer a toda hora o incômodo provocado pelas arestas da paisagem natal, o seu neoclassicismo é constantemente ameaçado por uma questão contextual.

A estratégia de Cláudio Manuel não deixa, no entanto, como vimos, de ser uma estratégia prevista dentro da tradição clássica: apropriar-se de mitos que remetam exatamente a situações de inadequação, de choque entre valores, de dilaceramento existencial. O que importa a nós, leitores de Cláudio Manuel da Costa no século XXI, é vislumbrar, através da retórica clássica universalizante que reveste a poesia do árcade mineiro, a sua capacidade de ver no mito literário um canal para a expressão de sua sensibilidade poética e para as reivindicações de seu tempo, mediante a apropriação de um discurso alheio que se torna instrumento em suas mãos.

E, por fim, se permitida uma leitura alegorizante da "Fábula do Ribeirão do Carmo", é no castigo mesmo infligido pelos deus greco-romano, quando da tentativa de apropriação do ideal árcade tentada pelo elemento local, que se inaugura, em literatura, o rio metonímico da pátria: Apolo, pai da artes, é, mesmo que às avessas, seu patrono e instituidor.

\section{A}

\section{A B STRACT}

The present paper examines some of the relations between the Greek-Roman mythical tradition and the European literary tradition in the poetry of Cláudio Manuel da Costa, pointing out the specific functions of myth and literature in the context of the neoclassical convention that characterizes the poetry of the author from Minas Gerais.

\section{KEYWORDS}

Myth, Tradition, Neoclassicism

\section{REFERÊNCIAS}

ARENDT, Hannah. A vida do espírito. 4. ed. Trad. Helena Martins. Rio de Janeiro: Relume Dumará, 2000. 392 p.

ALCIDES, Sérgio. Estes penhascos: Cláudio Manuel da Costa e a paisagem das Minas 1753-1773. São Paulo: Hucitec, 2003. 301 p.

BURKERT, Walter. Mito e mitologia. Trad. Maria Helena da Rocha Pereira. Lisboa: Edições 70, 2001. 81 p.

CANDIDO, Antonio. Formação da literatura brasileira (v. I). 7. ed. Belo Horizonte/Rio de Janeiro: Itatiaia, 1993. 334 p. 
GRIMAL, Pierre. A mitologia grega. 2. ed. Trad. Victor Jabouille. Mira-Sintra: Publicações Europa-América, 1989. 150 p.

HOLANDA, Sérgio Buarque de. Capítulos de literatura colonial. São Paulo: Brasiliense, 2000. 465 p.

OVÍDIO. As metamorfoses. Trad. David Gomes Jardim Junior. Rio de Janeiro: Ediouro, 1983. 297 p.

PIGLIA, Ricardo. Memoria y tradición. In: ANAIS DO $2^{\circ}$ CONGRESSO ABRALIC. Belo Horizonte, v. I, p. 60-66, 1991.

PROENÇA FILHO, Domício (Org.). A poesia dos inconfidentes. Artigos, ensaios e notas de Melânia Silva de Aguiar et al. Rio de Janeiro: Nova Aguilar, 1996. 1.200 p. 